УДК 66.974.434

\title{
ВЫПАРНАЯ УСТАНОВКА ДЛЯ ПРОИЗВОДСТВА ФУНКЦИОНАЛЬНЫХ ПРОДУКТОВ ПИТАНИЯ
}

\author{
Союстов Андрей Андреевич \\ студент \\ Научный руководитель: Терехова Ольга Николаевна \\ к.т.н., доцент \\ ФГБОУ ВО «Алтайский государственный \\ технический университет им. И.И. Ползунова»
}

\begin{abstract}
Аннотация: В статье рассматриваются функциональные продукты питания, для разных типов людей, рассматривается состав и возможный способ изготовления их. Рассматривается предлагаемая установка, которая может интенсифицировать процесс выпаривания пищевых сред с целью сгущения и уменьшения содержания воды, сохранения положительных качеств продукта, всех комплексов витаминов, которые при высоких температурах теряют свойства.

Ключевые слова: Выпаривание, функциональные продукты питания, состав продукта, ценность продукта, качество продукта, правильное питание.
\end{abstract}

\section{EVAPORATION PLANT FOR THE PRODUCTION OF FUNCTIONAL FOOD}

\section{Soyustov Andrey Andreevich}

student

Scientific supervisor: Olga Nikolaevna Terekhova,

Candidate of Technical Sciences, Associate Professor Altai State Technical University named after I.I. Polzunov

\footnotetext{
Abstract: The article discusses functional food products for different types of people, the composition and possible method of making them. The proposed unit, which can intensify the process of evaporation of food media in order to thicken and reduce the water content, preserve the positive qualities of the product, all vitamin complexes that lose their properties at high temperatures, is considered.
} 
Key words: Evaporation, functional food products, product composition, product value, product quality, proper nutrition.

Функциональные продукты питание в современном мире все больше и больше набирают оборот, сейчас каждый второй задумывается о правильном питании и о том, как сохранить свое здоровье, чтобы прожить больше. Этим обусловлено развитие одного из направлений пищевой промышленности, а именно производство функциональных продуктов питания, так называемых полезных продуктов (ПП), повышение их качества, например, в сторону увеличения количество белка, качества микрофлоры, что способствует повышению иммунитета организма человека. Также каждому человеку необходимо правильное питание и своя собственная диета, что в результате позволит добавить количество лет и улучшить качество жизни.

Сейчас одним из распространенных заболеваний у человека является ожирение, как одно из следствий нарушения здорового образа жизни и правильного питания, что в дальнейшем приводит к осложнениям и развитию серьезных заболеваний, таких как заболевание опорно-двигательного аппарата, диабет, сердечно-сосудистые заболевания, заболевания почек и печени, заболевания респираторного типа, которые у людей с избыточным весом протекают тяжелее и продолжительнее. Одной из самых главных причин ожирения является неправильное или нерациональное питание, наряду с малоподвижным образом жизни и усугубляемое большим количеством стрессовых ситуаций. Причем если раньше эта проблема касалась прежде всего людей старшего возраста, то теперь она все более становится актуальна среди молодежи и подрастающего поколения.

Люди привыкли получать удовольствие от приема пищи, не глядя на количество получаемых с ней калорий, которое в обычном джеме или соке иногда достигает до 500 Ккал на 100 грамм, что составляет дневную норму, которую мы употребляем помимо всего прочего за один прием пищи, а таких приемов в свою очередь может быть несколько, а значит, мы поглощаем огромное количество энергии, которое организму некуда тратить и он начинает запасать его под кожей в виде слоев жира, что бы когда-нибудь его использовать, как запасную энергию. Но такой период может не настать, и мы будем с каждым разом наедать и наедать лишние килограммы. Одним из путей снижение потребляемых калорий является использование продуктов с 
сахарозаменителями, например, низкокалорийных джемов (Рис.1) и низкокалорийных сиропов (Рис.2), низкокалорийные соусы:

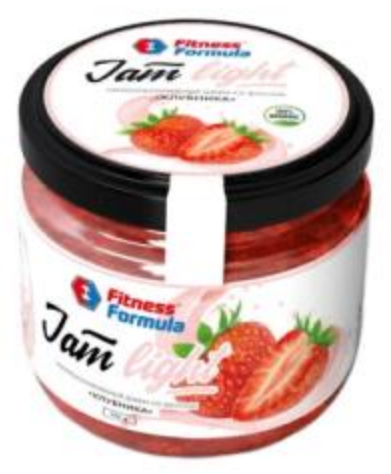

Рис. 1. Низкокалорийный джем от Fitness Formula

\section{Puc. 2. Fitness Formula Cocktail Syrup}

Низкокалорийный джем от Fitness Formula (Рис.1) идеально подойдет, если Вы находитесь на диете или придерживаетесь правильного питания. При соблюдении диеты, очень хорошо подходит к творогу или при употреблении мяса, можно добавить немного сладости, например, в чай вместо сахара, а при правильном питании можно добавлять такой продукт к блинам, к выпечке, намазывать на слайсы, хлебцы. 


\section{Питательная ценность на 100 мл:}

Калории: 2 Ккал

Белки: 0 г

Углеводы: 0,3 г

Жиры: 0 г

Клетчатка: 1 г

\section{Состав:}

Подготовленная столовая вода, концентрированный натуральный яблочный сок, загуститель КМЦ, пектин (клетчатка), стабилизатор агар-агар, подсластитель сукралоза, регулятор кислотности - лимонная кислота, ароматизатор натуральный клубника, краситель натуральный, консервант бензоат натрия.

Такой джем подойдет для всех людей, с широким разнообразием вкусов, можно подобрать под каждого, то, что ему нравится, и то, что в его составе нет большого количества калорий, его можно скушать и не думать, что отложиться он в жир или нет.

В данном джеме используется подсластитель суркалоза, этот подсластитель был синтезирован из сахара, но в нем почти нет калорий, однако на вкус он слаще в 600 раз сахара, что позволяет уменьшить количество потребления, но увеличить вкусовые свойства блюда. Также в данном джеме используется концентрированный натуральный яблочный сок, который получается путем выпаривания на специальных выпарных установках стандартных серийно выпускаемых конструкций, чаще всего это кожухо-трубные теплообменные аппараты [1, стр.116]. Однако для сохранения всех полезных свойств готового продукта необходимы щадящие режимы обработки сырья, что может обеспечить только современный подход к способам и конструкциям используемых аппаратов.

Вообще процесс выпаривания - процесс, при котором получают концентрат из жидких растворов, он применим к летучим жидкостям, в которых растворены нелетучие. В процессе кипения жидкость упаривается и изменятся ее консистенция и увеличивается концентрация сухих веществ.

Сейчас процесс выпаривания - один из популярных среди первоначального обезвоживания или концентрирования, в таких производствах как молочное, производство фруктовых и овощных соков, сахарной промышленности, для получения лекарственных средств, концентратов. Выпаривание используется для сгущения молока и молочных 
продуктов, свекольного сока при производстве сахара, томатного сока при получении томатной пасты и т.д.

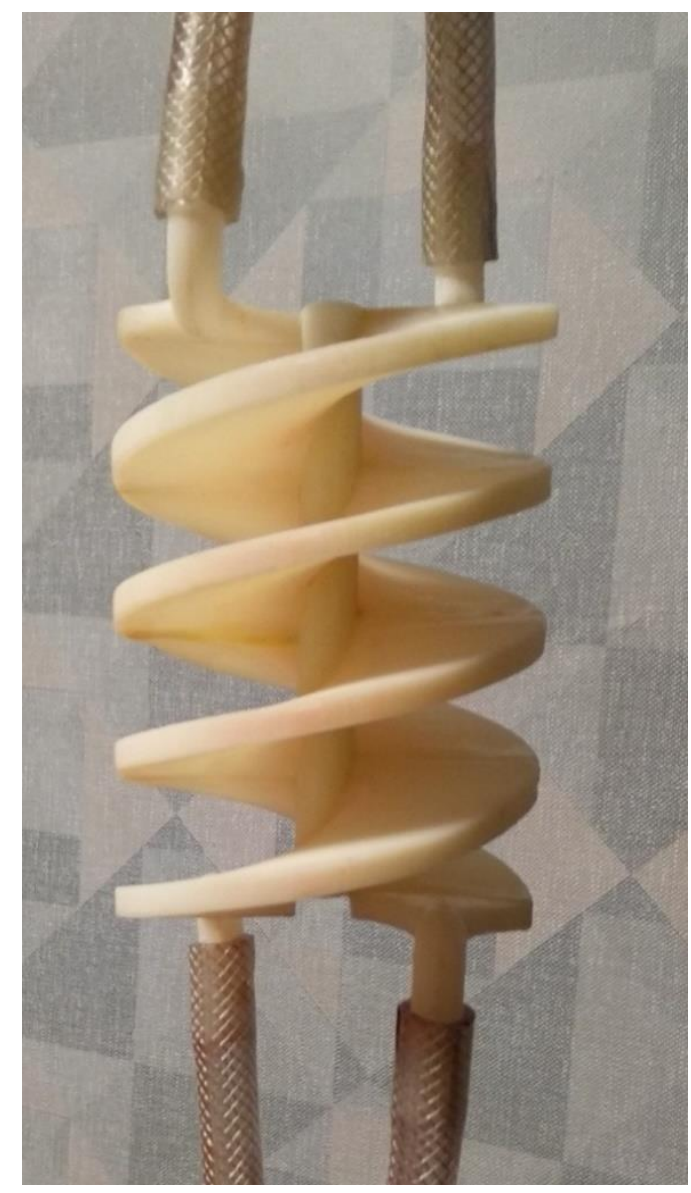

\section{Рис. 3 Собранная 3D модель предложенной выпарной установки}

Для повышения качества сока и сохранение полезных свойств, нами предложена новая конструкция выпарной установки, рабочий элемент которой выполнен в виде двойной винтовой поверхности.

Для визуализации устройства и лучшего понимания процесса работы, был разработан $3 \mathrm{~d}$ макет выпарной установки, в котором показано действие рабочего органа - греющего пара (Рис. 3).

Описание и принцип работы данной установки:

Исходный раствор, поступая в корпус, разделяется и подается на две винтовых поверхности, внутри которых проходит греющий пар. Сама винтовая поверхность состоит из двух шнеков полых внутри, каждый шнек зафиксирован и не вращается. Исходный раствор, который движется по поверхности шнека, нагревается быстро, и начинается процесс кипения и упаривания исходного раствора. т.к. шнек подогревается греющим паром, а 
также, шнек, который идет выше, тоже дает тепло и таким образом получается, что исходный раствор выпаривается и выделяет вторичный пар, который по шнекам будет подниматься вверх, поддерживая температуру греющего пара. В конце процесса весь выпаренный раствор попадает в одну трубу и уходит из выпарной установки.

Преимущества предлагаемой установки:

Исходный раствор не скапливается, а по спирали опускается вниз, не занимая рабочую поверхность теплообмена. Витки спирали полые внутри и в них двигается греющий пар, это позволяет нагревать исходный раствор в разы быстрее до температуры кипения, начала процесса упаривания жидкости. В установке расположено 2 витка, которые дают возможность загружать большее количество исходного раствора, что ускорит прохождения единицы массы раствора за единицу время, также количество витков можно регулировать под каждые нужды пищевого производства. Из-за особенностей своей конструкции, данная установка может заменить многокорпусные выпарные установки, т.к. количество проходимого упаренного раствора может быть большое. Температурный баланс в выпарной установке будет эффективным, т.к. греющий пар будет нагревать шнек, и он будет отдавать тепло на верхнюю поверхность и на нижнюю, что будет нагревать исходный раствор. А также вторичный пар будет поддерживать температуру греющего пара, т.к. будет подниматься по нижней части шнека, расположенного выше. Таким образом, потери по температуре будут минимальные.

Представленное новое конструктивное решение выпарной установки предназначено для сгущения жидких пищевых сред, для производства продуктов функционального назначения, такие продукты как в спортивной индустрии: низкокалорийные соусы, низкокалорийные джемы, для предварительного сгущения витаминных жидкостей, так же такую установку можно использовать в фармакологическом направлении, приготовление лекарственных сиропов, с повышенной концентрацией лечебных веществ, что позволит повысить дозировку веществ на один миллилитр, грамм.

Таким образом, эта установка поможет многим отраслям, где необходим непрерывный процесс, в котором необходимо высокое и точное качество готового продукта, повышения эффективности работы типовых линий производства, для приготовления обычных продуктов питания, таких как сгущенное молоко, томатная паста, свекольные соки и т.п. 
Данная установка была представлена на Всероссийском конкурсе проектных работ «Я проектирую будущее» и вошла в число победителей. Заняла первое место в 18-й Всероссийской научно-технической конференции студентов, аспирантов, молодых ученых «Наука и Молодежь» [2, стр.260] в секции «Машины и аппараты пищевых производств». С Данной установкой участвовали в IV Межрегиональной научно-практической конференции (с международным участием) «От Биопродуктов к Биоэкономике».

\section{Список литературы}

1. Вобликова, Т. В. Процессы и аппараты пищевых производств : учебное пособие / Т. В. Вобликова, С. Н. Шлыков, А. В. Пермяков. - 4-е изд., стер. - Санкт-Петербург : Лань, 2019. - 204 с. - ISBN 978-5-8114-4163-1. Текст : электронный // Лань : электронно-библиотечная система. - URL: https://e.lanbook.com/book/115658 (дата обращения: 18.10.2021).

2. Установка для выпаривания пищевых сред. Союстов А. А., бакалавр кафедры МАПП, научный руководитель: Терехова О.Н., к.т.н., доцент. Наука и молодежь: материалы XVIII Всероссийской научно-технической конференции студентов, аспирантов и молодых ученых (19-23 апреля 2021 года, г. Барнаул): в 2 т. / Алтайский государственный технический университет им. И. И. Ползунова; отв. редактор А.О. Хребто. - Барнаул: АлтГТУ, 2021. - Том 1, Часть 2. - с. 259-261.

(C) А.А. Союстов, 2021 